\title{
Processing and Interpretation of Remote Sensing Data, Received from the Belarusian Space Apparatus Using ENVI and ArcGIS
}

\author{
Maria O. Eroshevich, Vera R. Ermakovich, Vladimir A. Saechnikov \\ Belarusian State University, Minsk, Belarus \\ ermakovichvr@gmail.com
}

\begin{abstract}
The results of practical work with satellite images obtained from the Belarusian spacecraft are presented. A method was developed for creating an interactive information system "Narochanskaya Lakes Group". Working with RGB in the ENVI program and preparing images for thematic processing and analysis of data in the ArcGIS program. This work is an interpretation of remote sensing data obtained from the Belarusian spacecraft using ENVI and ArcGIS.
\end{abstract}

Keywords: "Narochanskaya Lakes Group", Belarusian spacecraft, space image, remote sensing data, RGB, PO 


\title{
ОБРАБОТКА И ИНТЕРПРЕТАЦИЯ ДАННЫХ ДИСТАНЦИОННОГО ЗОНДИРОВАНИЯ, ПОЛУЧЕННЫХ С БЕЛОРУССКОГО КОСМИЧЕСКОГО АППАРАТА СРЕДСТВАМИ ЕNVI и ArcGIS
}

\author{
М.О. Ерошевич, В.Р. Ермакович, В.А. Саечников \\ Белорусский государственный университет, Минск, Беларусь \\ ermakovichvr@gmail.com
}

\begin{abstract}
Представлены результаты практической работы с космоснимками, полученными с Белорусского космического аппарата. Выработана методика создания интерактивной информационной системы «Нарочанская группа озер». Проведена работа по улучшению яркости и контрастности снимков, работа с каналами RGB в программе ENVI и подготовка снимков для проведения тематической обработки и анализа данных в программе ArcGIS. Целью данной работы является обработка и интерпретация данных дистанционного зондирования, полученных с белорусского космического аппарата средствами ENVI и ArcGIS.
\end{abstract}

Ключевые слова: «Нарочанская группа озер», Белорусский космический аппарат БКА, космоснимок, данные дистанционного зондирования, RGB, ПО.

\section{Введение}

Дистанционные методы исследования представляют собой многосложную и разностороннюю область науки и техники. Оперативность получения данных ДЗ3, глобальность охвата обследуемой территории, информативность и высокая разрешающая способность изображений местности, полученных такими средствами, гораздо выше, чем у традиционных способов получения необходимой информации [1]. Поэтому, учитывая все положительные стороны, высокую эффективность использования результатов анализа и обработки информации дистанционного зондирования из космоса, а также перспективу выхода страны на международный рынок с данным направлением, создание Белорусской космической системы дистанционного зондирования (БКСДЗ) является одной из актуальнейших задач Республики Беларусь.

БКА оснащен панхроматической съемочной системой (ПСС), которая имеет один спектральный канал, позволяющий получать черно-белые снимки с разрешение 2,1 м, и мультиспектральной съемочной системой (МСС) для получения снимков с разрешением 10,5 м в четырех спектральных диапазонах. Орбита круговая солнечно-синхронная высотой $510 \pm 10$ км, кратность орбиты 16 сут, полоса захвата 20 км, масса 474 кг. БКА за пять лет заснял более 120 млн кв.км территории Земли. Это пятая часть суши.

Данные ДЗ - это аэрокосмические снимки, которые представляются в цифровой форме в виде растровых изображений. Поэтому обработка и интерпретация ДДЗ непосредственно связана с цифровой обработкой изображений [2].

Обработка данных ДЗ включает предварительную обработку и улучшение изображений. В процессе предварительной обработки из данных удаляются систематические радиометрические и геометрические ошибки. Улучшение изображения позволяет преобразовать его в форму, наиболее удобную для визуального или машинного анализа и используется для того, чтобы подчеркнуть важнейшие признаки изображения и в дальнейшем облегчить задачу интерпретации данных. 
Для учебного процесса, проводимого по спецкурсу «ГИС-технологии» на факультете радиофизики и компьютерных технологий, предоставление снимков с БКА производилось следующим образом: обозначили и выделили на карте снимки определенной территории, и если они соответствовали возможностям и всем заявленным требованиям, то они предоставлялись согласно договору, заключенному между УП «Геоинформационные системы» и БГУ.

\section{Создание интерактивной информационной системы «Нарочанская группа озер» средствами ENVI и ARcGIS}

Исходные данные для выполнения работы - космоснимки «Нарочанская группа озер» с белорусского космического аппарата БКА (панхроматический и мультиспектральный) и топографическая карта Мядельского района Минской области масштаба 1:100000.

Для создания интерактивной информационной системы «Нарочанская группа озер» необходимо выработать методику, которая заключалась в следующем: в ПО ENVI улучшить контрастность космоснимка; изменить каналы RGB для распознавания объектов на космоснимке; конвертировать снимок из ENVI в ArcGIS; создать шейп-файл в приложении ArcCatalog, добавить новый шейп-файл в приложение ArcMap, оцифровать озера на космоснимке; подписать созданные объекты; рассчитать площадь озер с помощью модуля ArcToolBox; провести анализ полученных данных.

Работа по созданию интерактивной карты проводилась в программных продуктах ENVI и ArcGIS. B ENVI проводилось улучшение контрастности и изменение каналов RGB для распознавания объектов на снимке. B ArcGIS проводилась оцифровка снимка, подпись объектов и расчёт площадей озер.

В работе входными данными являются панхроматический и мультиспектральный снимки территории национального парка «Нарочанская группа озер» (рис. 1). Оба снимка уже прошли предварительную обработку и трансформацию. На снимках визуально идентифицируются озера Нарочь, Белое, Мястра, Мядель.
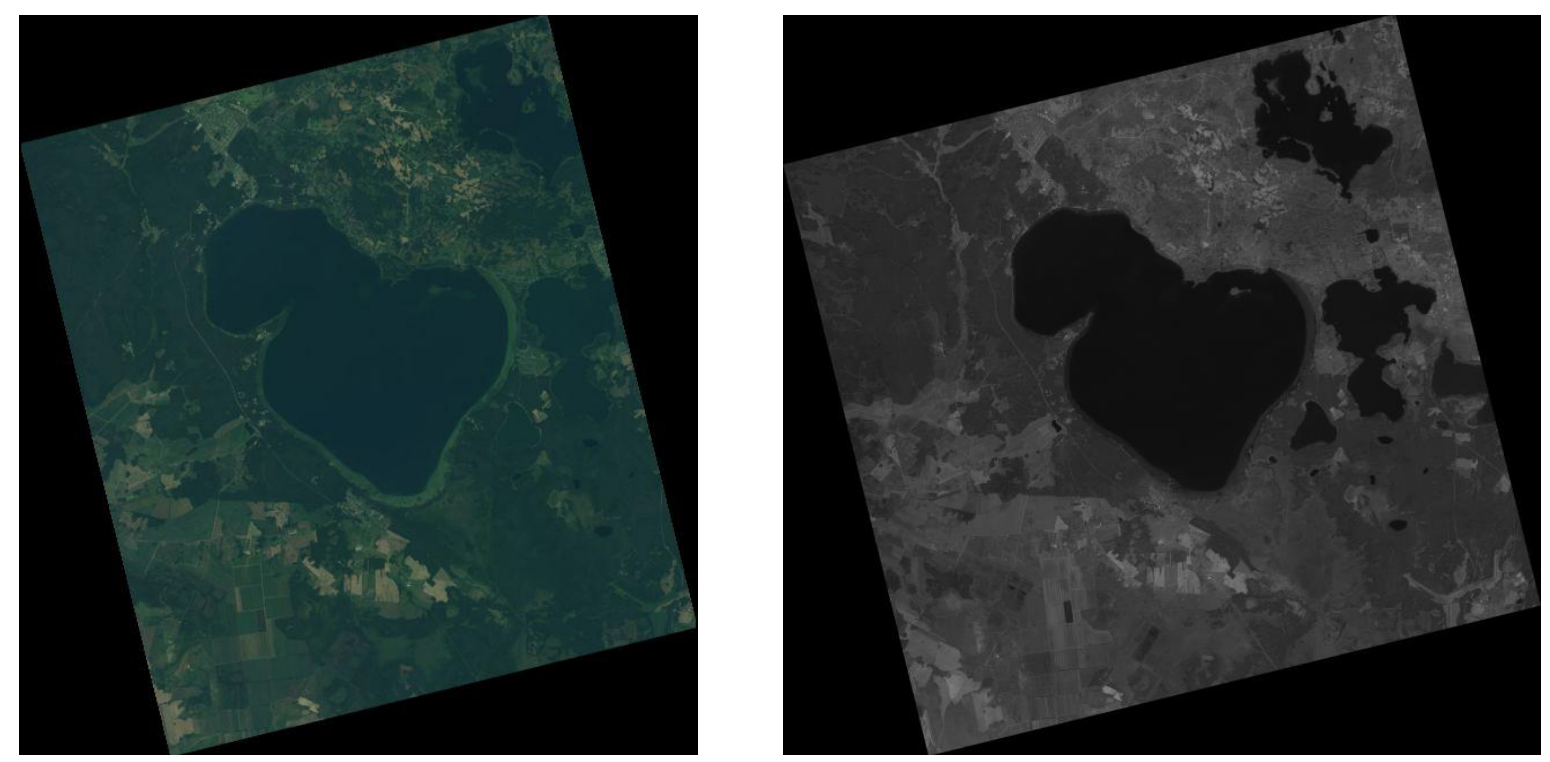

Рис. 1. Исходные мультиспектральный и панхроматический снимки с БКА

Открываем мультиспектральный снимок (Рис. 1) в программном продукте ENVI.

Улучшаем контрастность снимка. ENVI предоставляет различные методы улучшения контрастности [3]. Для данного снимка применим линейный метод улучшения контрастности. После улучшения контрастности изображения на космоснимке можно рассмотреть лес - темнозеленого цвета, населенные пункты - бледно желтый цвет, сельскохозяйственные угодья - серый цвет, озера - черный цвет (Рис. 3.).

Изменим каналы RGB. Изменение каналов RGB космоснимка проводится для распознавания объектов. На рисунке 4 после изменения RGB канала и улучшения контрастности 
линейным методом хорошо распознаются лесной массив - зеленый цвет, жилые пункты - серый цвет, салатовый цвет - поля, озера - черный цвет.
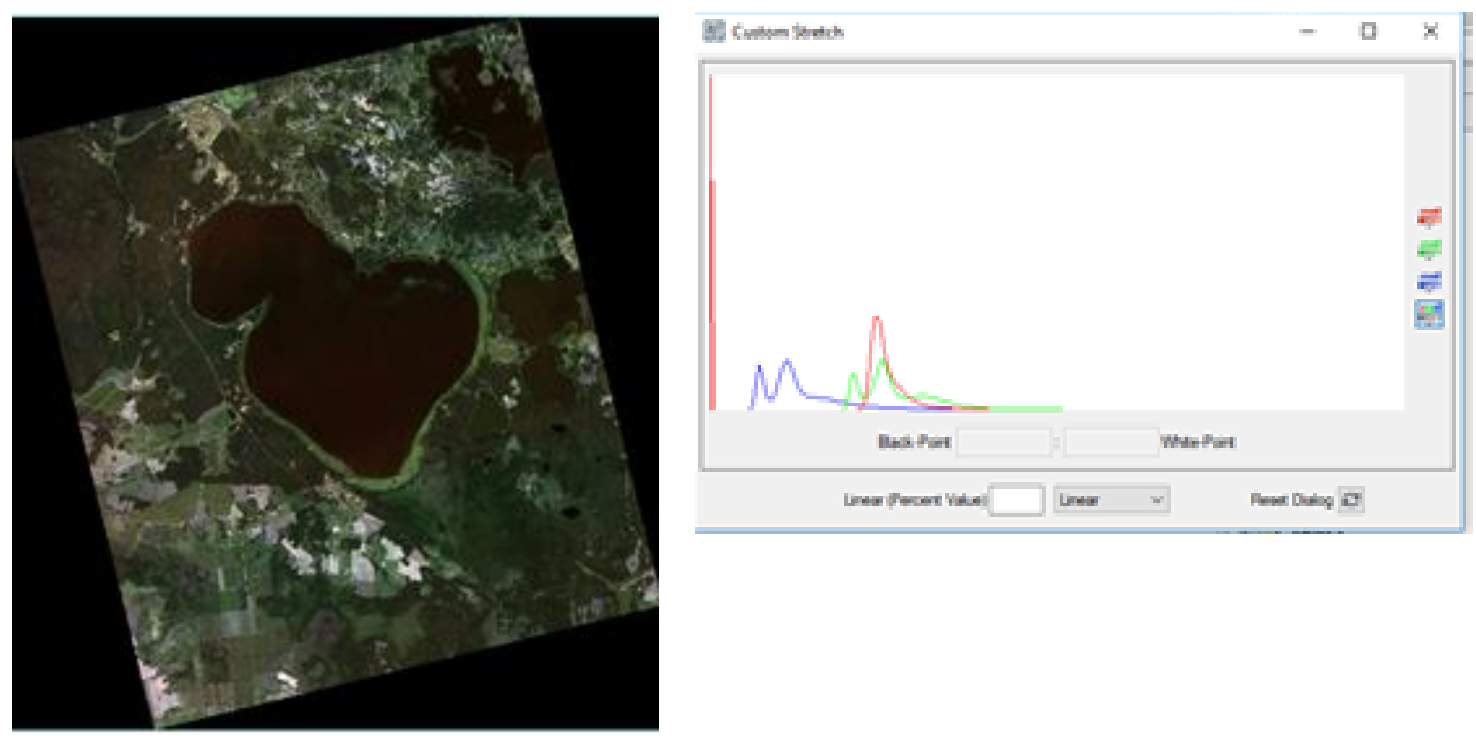

Рис. 3. Изображение с улучшенной контрастностью линейным методом и гистограмма трех каналов

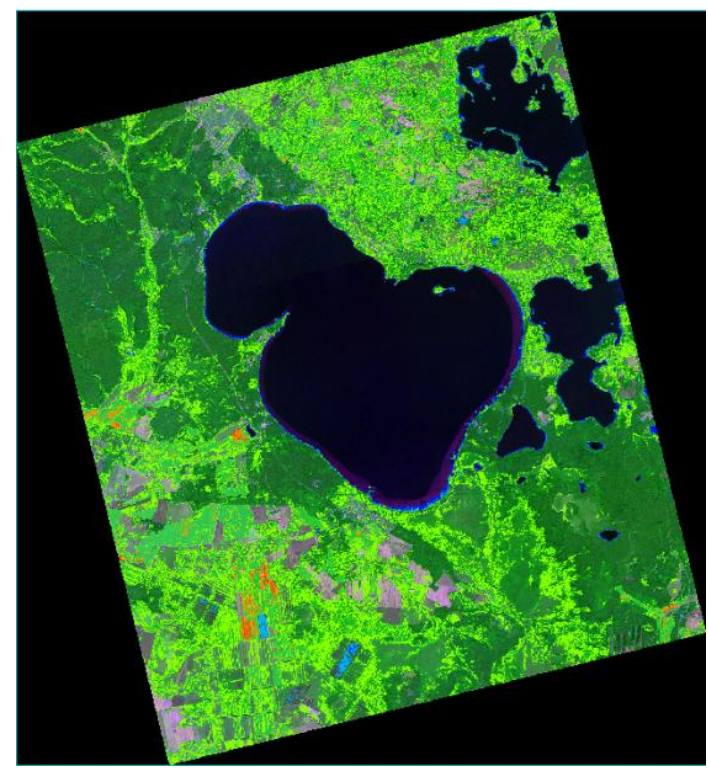

Рис. 4. Мультиспектральный снимок с измененными спектральными каналами и улучшенной контрастностью линейным методом

Переконвертируем космоснимок из ENVI в ArcGIS и откроем обработанный снимок в ArcGIS. Программа содержит два приложения - приложение ArcCatalog - приложение для управления данными и ArcMap - приложение для отображения данных [4].

B приложении ArcCatalog создадим новый шейп-файл, тип объекта - полигон. Перейдем в приложение ArcМар и добавим новый шейп-файл на карту. С помощью инструмента Редактор оцифруем площадь, которую занимает озеро Нарочь и другие озера. Для наглядности и информативности создадим подписи озер. Проделанная работа представлена на рисунках 5 и 6. 


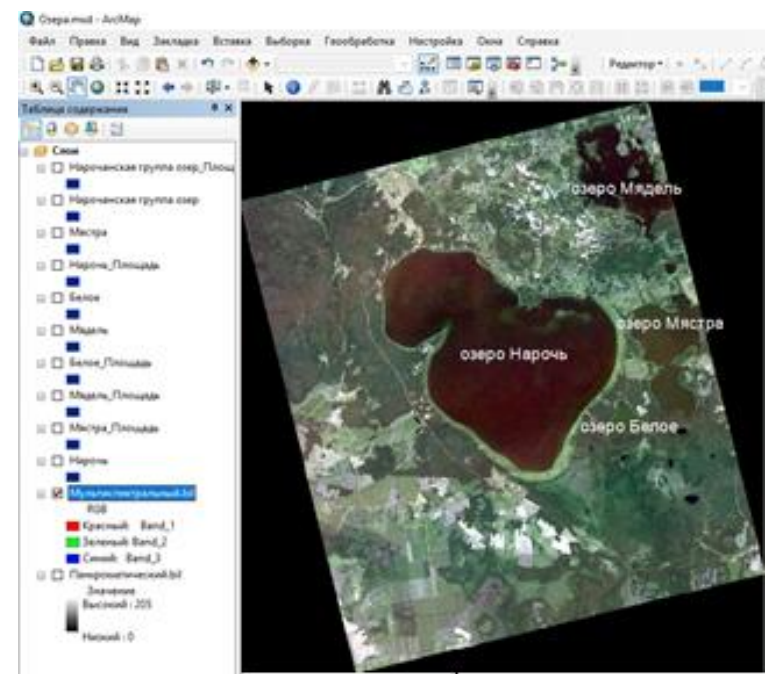

Рис. 5. Мультиспектральный снимок в ArcMap

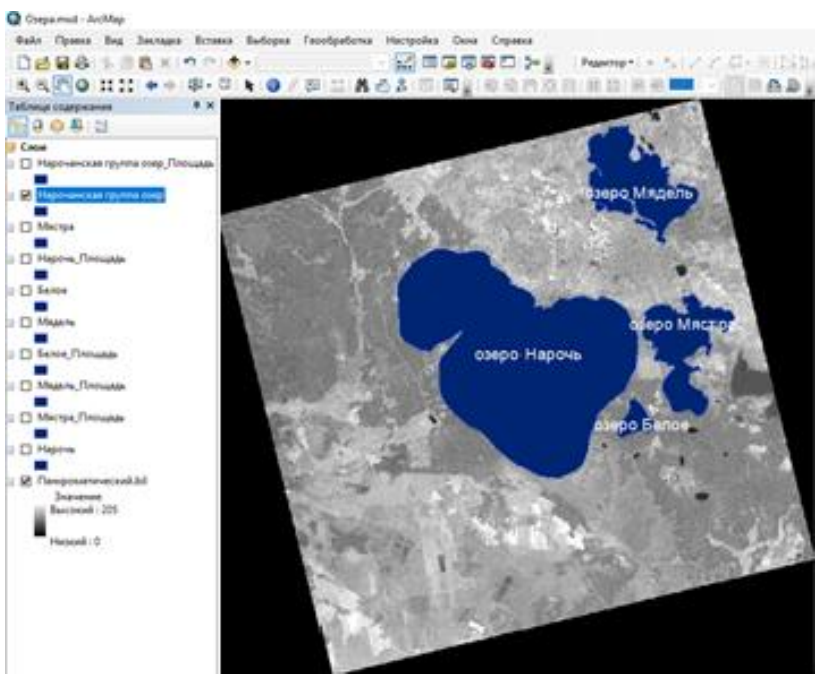

Рис. 6. Панхроматический снимок в ArcMap

Для определения площади полигона воспользуемся инструментом Пространственная статистика / Утилиты / Вычислить площади модуля ArcToolbox.

В результате работы этого инструмента создаются новые объектные классы, содержащие те же самые пространственные объекты, но с расширенными атрибутами. Атрибутивная таблица дополняется новым полем F_AREA, содержащим значение площади полигонального объекта. На рисунке 7 представлена таблица площадей Нарочанской группы озер: 0 - озеро Нарочь, 1 - озеро Белое, 2 - озеро Мястра, 3 - озеро Мядель.

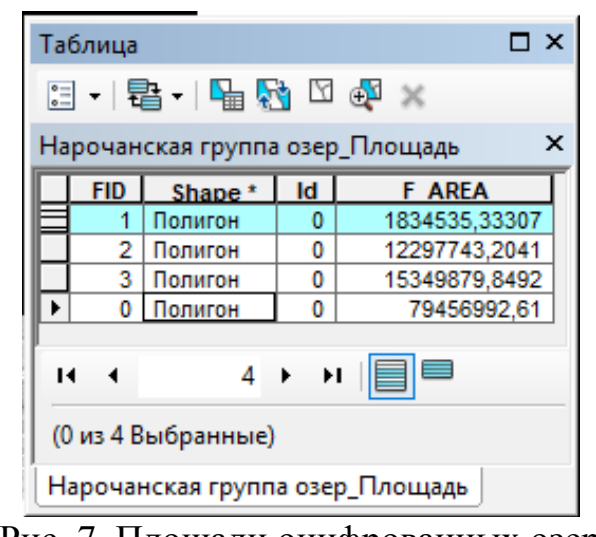

Рис. 7. Площади оцифрованных озер

Из справочных данных водохранилищ Беларуси площади озер: Нарочь - 79,2 км², Белое - 1,95 км², Мястра - 13,1 км², Мядель - 16,2 км².

Проведем наложение карты 1:100000 на космоснимок. Сделаем верхний слой прозрачным. В результате работы наши два снимка: космоснимок и растровое изображение 1:100000 полностью совпали (рис.8). 


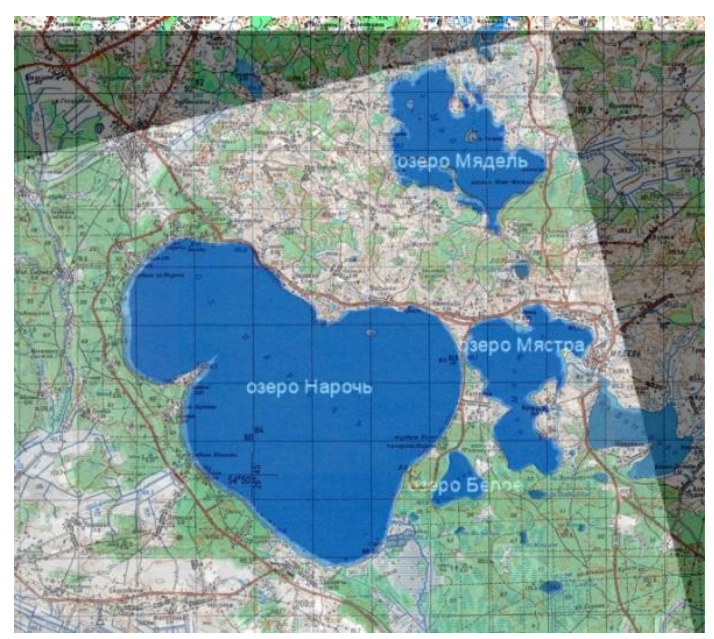

Рис. 8. Наложение карты 1:100000 на космоснимок

По результатам проведенной работы можно сделать вывод о небольшом изменении береговой линии озера Нарочь.

Состояние местности карты 1:100000 представлено на 1980 г., космоснимок территории Беларуси - дата съемки 2018 г.

Создание интерактивной информационной системы «Нарочанская группа озер» позволит повысить информативность и доступность быстрого получения информации по данным объектами и территориям, а также использовать разновременные космоснимки с Белорусского космического аппарата при проведении экологического мониторинга.

Работа может иметь практическое применение в учебном процессе, проводимом на кафедре физики и компьютерных технологий по спецкурсу «ГИС-технологии» для студентов специальностей «Аэрокосмические радиоэлектронные и информационные системы и технологии» и «Радиофизика».

\section{References}

[1] Chandra, A. M., Gosh, C. K. Remote sensing and geographic information systems. - Moscow: Technosphere, 2008. - 312 p. (In Russian)

[2] Sutyrina, E. N. Remote sensing of the earth: a training manual. - Irkutsk: Publishing house of ISU, 2013. - 165 p. (In Russian)

[3] Tokareva, O. S. Processing and interpretation of Earth remote sensing data. - Tomsk: Publishing house of Tomsk Polytechnic University, 2010. - 148 p. (In Russian).

[4] Ermakovich V. R., Sayechnikov V. R., Verkhoturov V. A. Processing and analysis of Earth remote sensing data using ESRI software [Electronic resource]: manual, Minsk. - 2012. (In Russian) 